\title{
CONDUTIVIDADE ELÉTRICA DA SOLUÇÃO NUTRITIVA PARA O CULTIVO DO CRISÂNTEMO EM VASO ${ }^{(1)}$
}

\author{
Márkilla Zunete Beckmann-Cavalcante ${ }^{(2)}$, Kathia Fernandes Lopes Pivetta ${ }^{(3)}$, \\ Ítalo Herbert Lucena Cavalcante ${ }^{(2)}$, Lourival Ferreira Cavalcante ${ }^{(4)}$, Paulo \\ Affonso Bellingieri ${ }^{(3)}$ \& Milton César Costa Campos ${ }^{(5)}$
}

\begin{abstract}
RESUMO
Em se tratando do crisântemo de vaso, que constitui relevante contribuição à atividade de plantas ornamentais, ainda há necessidade de uma recomendação consistente sobre a condutividade elétrica (CE) da solução nutritiva para seu cultivo. Nesse sentido, realizou-se um experimento em ambiente protegido, objetivando avaliar o crescimento do crisântemo cv. Miramar cultivado em vaso, em função da CE da solução nutritiva e da lixiviação de sais do substrato. O delineamento experimental foi em blocos casualizados, com quatro repetições; os tratamentos foram distribuídos em esquema fatorial $5 \times 2$, referentes aos valores de CE da solução nutritiva $\left(2,1 ; 2,8 ; 3,5 ; 4,2 ; \mathrm{e} 4,9 \mathrm{dS} \mathrm{m} \mathrm{m}^{-1}\right)$, em substrato com e sem lavagem para lixiviação dos sais. O aumento da CE inibiu o crescimento e desempenho vegetativo, mas estimulou o diâmetro da haste. A lixiviação dos sais estimulou, exceto quanto ao diâmetro da haste, o maior crescimento avaliado pelas demais variáveis fitotécnicas. A CE de $2,1 \mathrm{dS} \mathrm{m}^{-1}$ possibilita a produção de crisântemo dentro de padrões qualitativos de comercialização, mediante lixiviação periódica do substrato.
\end{abstract}

Termos de indexação: Dendranthema grandiflora Tzvelev., lixiviação, substrato.

\footnotetext{
(1) Parte da Tese de Doutorado do primeiro autor apresentada ao Curso de Pós-Graduação em Agronomia da Faculdade de Ciências Agrárias e Veterinárias da Universidade Estadual Paulista (UNESP). Recebido para publicação em maio de 2009 e aprovado em abril de 2010.

(2) Professor(a) do Departamento de Engenharias, Campus Prof ${ }^{\text {a }}$ Cinobelina Elvas (CPCE), Universidade Federal do Piauí UFPI. BR 135, CEP 64900-000 Bom Jesus (PI). E-mails: zunete@ufpi.edu.br; italohlc@ufpi.edu.br

(3) Professor(a) da Faculdade de Ciências Agrárias e Veterinárias, Universidade Estadual Paulista - FCAV/UNESP. Via de Acesso Prof. Paulo Donato Castellane s/n, CEP 14884-900 Jaboticabal (SP). E-mail: kathia@fcav.unesp.br; pabellin@fcav.unesp.br

(4) Professor Associado do Centro de Ciências Agrárias, Universidade Federal da Paraíba - UFPB. Campus II, CEP 58397-000 Areia (PB). E-mail: lofeca@cca.ufpb.br

(5) Professor do Instituto de Agricultura e Ambiente, Universidade Federal do Amazonas - UFAM. Av. General Rodrigo Otávio 3000, CEP 69077-000 Manaus (AM).E-mail: mcesar@ufam.edu.br
} 


\title{
SUMMARY: ELECTRICAL CONDUCTIVITY OF NUTRIENT SOLUTION FOR CHRYSANTHEMUM POT CULTIVATION
}

\begin{abstract}
For the cultivation of potted chrysanthemum, which is a relevant culture in the sector of ornamental plants, there is still a need of a consistent recommendation of electrical conductivity of the nutrient solution. An experiment was conducted in a greenhouse to study the effect of electrical conductivity of nutrient solution and salt leaching on the growth of pot chrysanthemum, cv. Miramar. A completely randomized block design was used, with four replications and treatments distributed in a $5 \times 2$ factorial arrangement, representing the electrical conductivity (EC) levels of nutrient solution, $E C=2.1 ; 2.8 ; 3.5 ; 4.2$ e $4.9 \mathrm{dS} \mathrm{m} \mathrm{m}^{-1}$, in substrate with and without salt percolation. Increasing EC inhibited plant development, but stimulated stem diameter. Salt leaching resulted in greater growth of the plant variables, except for stem

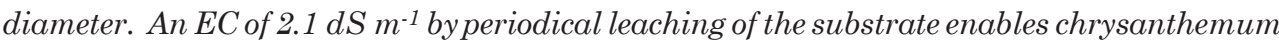
production to obtain market quality standards.
\end{abstract}

Index terms: Dendranthema grandiflora Tzvelev., leaching, growth medium.

\section{INTRODUÇÃO}

Dentre os principais produtos da floricultura brasileira, destaca-se o crisântemo (Dendranthema grandiflora Tzvelev.), tanto como flor de corte quanto em vaso. Seu sucesso é atribuído à expressiva resposta ao comprimento do dia (fotoperíodo) para a indução floral, à diversidade de cores e formas, à resistência ao transporte, à longa durabilidade e à fácil adaptabilidade a diferentes regiões (Barbosa, 2003).

Na floricultura, em que a competição por mercados é intensa, uma das grandes limitações de produtividade é o manejo rígido de fatores ambientais. Além disso, a expansão da cultura enfrenta também obstáculos da carência de informações técnicas sobre seu cultivo, como o conhecimento das necessidades nutricionais da cultura, o que está intrinsecamente relacionado à adubação, a qual, juntamente com a nutrição, pode levar à perda de qualidade, produtividade e longevidade das inflorescências e da planta. Há também a possibilidade de gerar impactos ambientais e revestir-se de grande relevância econômica, uma vez que contribui para a diminuição dos custos de produção devido ao uso racional da utilização qualitativa e quantitativa de fertilizantes (Nell et al., 1997; Röber, 1999).

Muitas flores e plantas ornamentais são cultivadas em vasos, empregando-se substratos como meio de cultivo, tornando necessária a aplicação de soluções nutritivas com concentrações de nutrientes adequadas às plantas. Entretanto, no Brasil, a maioria dos produtores segue padrões de adubação previamente estabelecidos e que, muitas vezes, não refletem a real exigência da cultura, podendo promover desbalanço nutricional nas plantas e incremento de sais no substrato, refletindo em aumento da condutividade elétrica (CE), o que, acima de limites ótimos, resulta em perda de produtividade e qualidade dos produtos (Cavalcante et al., 2002; Cavalcante \& Cavalcante, 2006).

No preparo das soluções e no emprego das dosagens recomendadas, mesmo em doses menores, registramse aumentos na condutividade elétrica de toda e qualquer solução. Nesse sentido, o contínuo monitoramento dos teores de sais solúveis nas soluções nutritivas e no substrato é um dos critérios para prevenir a expansão dos processos de salinização, em resposta às concentrações dos fertilizantes utilizados, dentre os quais os nitrogenados e potássicos são os de maiores índices salinos (Hu \& Schmidhalter, 2004).

Uma das maneiras de controlar o acúmulo de sais no substrato é aplicar periodicamente lâminas de água para a lixiviação dos sais fornecidos a partir da solução nutritiva (Burgueño, 1996), mantendo o substrato com $\mathrm{CE}$ oscilando dentro da faixa adequada para o crescimento e desenvolvimento vegetal. Por outro lado, ainda faltam na literatura trabalhos que permitam identificar a CE adequada para a melhor produção do crisântemo em vaso, devido às diferentes variedades no mercado.

Considerando o exposto, o presente trabalho objetivou avaliar o crescimento do crisântemo cv. Miramar em vaso, em função da condutividade elétrica da solução nutritiva e da lixiviação de sais do substrato.

\section{MATERIAL E MÉTODOS}

\section{Caracterização da área experimental}

O experimento foi conduzido em ambiente protegido no Setor de Plasticultura do Departamento de 
Engenharia Rural da Faculdade de Ciências Agrárias e Veterinárias (FCAV) da Universidade Estadual Paulista (UNESP), Jaboticabal, São Paulo, Brasil, localizado em altitude média de $600 \mathrm{~m}$.

No período experimental, registraram-se no ambiente protegido temperaturas média, média da mínima e média da máxima, respectivamente, de 23,2 , 19,1 e $31,6^{\circ} \mathrm{C}$ e umidade relativa média do ar de $74,4 \%$, média mínima de $47 \%$ e média máxima de $92 \%$.

\section{Tratamentos e delineamento experimental}

O delineamento experimental adotado foi em blocos casualizados, com tratamentos distribuídos em esquema fatorial $5 \times 2$, referentes aos valores de CE da solução nutritiva $\left(2,1 ; 2,8 ; 3,5 ; 4,2 ;\right.$ e $\left.4,9 \mathrm{dS} \mathrm{m}^{-1}\right)$, em substrato com (SCL) e sem (SSL) lavagem com água destilada para a lixiviação de sais, com quatro repetições.

\section{Condução do experimento e tratos culturais}

Estacas de crisântemo (Dendranthema grandiflora Tzvelev.) cultivar Miramar, de cor amarela, com inflorescências do tipo margarida oriundas de um único lote de mesma idade, foram adquiridas na empresa comercial Dekker de Wit ${ }^{\mathbb{R}}$, sendo cultivadas seis estacas previamente tratadas com ácido indol-butírico (AIB) em cada vaso de polietileno número 14 com volume de 1,2 L (altura de $12 \mathrm{~cm}$, base superior e base inferior com 14 e 9,4 cm de diâmetro, respectivamente), contendo substrato comercial para plantas ornamentais (Terra do Paraíso 3010).

Aos 14 dias após o início do enraizamento (DAE), quando apresentavam cinco a seis folhas abertas, realizou-se o desponte (pinch) e considerou-se essa data o tempo zero de avaliação.

Durante o período de enraizamento foi providenciada iluminação artificial, o que promoveu dias com mais de $13 \mathrm{~h}$ de luz, utilizando-se lâmpadas incandescentes de $100 \mathrm{~W}$, instaladas a $1,2 \mathrm{~m}$ de altura e espaçadas de 1,0 x 1,0 m. Estas foram ligadas no período noturno, alternando automaticamente intervalos de luz com intervalos de escuro para favorecer o crescimento vegetativo. Essa operação foi realizada diariamente até o $14^{\circ}$ dia depois do enraizamento (DAE). Após esse período, as plantas passaram para a fase dos dias curtos (dias com menos de $13 \mathrm{~h}$ de luz) a partir do escurecimento artificial promovido por lonas de polietileno pretas, para a indução floral. Esse manejo seguiu as recomendações de Motos \& Oliveira (s.d), totalizando 12 semanas de cultivo.

Os vasos foram mantidos livres de plantas daninhas e foi realizado o controle fitossanitário preventivo à base de produtos e doses adequadas à cultura, utilizando Imidacloprid (70 \%) para prevenção da mosca-branca e Deltamethrin (25\%) para controle da mosca-minadora. O regulador de crescimento B-Nine ${ }^{\circledR}$ (Daminozide $85 \%$ ), $2 \mathrm{~g} \mathrm{~L}^{-1}$, foi aplicado três vezes durante o ciclo, aos 14,28 e $42 \mathrm{DAE}$, conforme recomendações de Motos \& Oliveira (s.d.).

O manejo da fertirrigação foi baseado no método da pesagem, em que cinco vasos com plantas de cada tratamento, com drenos na parte inferior, foram inicialmente saturados com água não salina, até iniciarem a drenagem. Após cessar a drenagem, os vasos foram pesados para obtenção do peso úmido inicial $\left(\mathrm{U}_{i}\right)$, correspondente à capacidade de vaso. Obteve-se dessa maneira o valor do vaso + substrato úmido + planta referente a cada tratamento, que foi utilizado como referência para as irrigações subsequentes até o final do experimento. Para repor a quantidade de solução (QS) consumida (evapotranspirada) referente ao dia anterior, procedia-se novamente à pesagem dos vasos, obtendo-se a umidade média final $\left(\mathrm{U}_{f}\right)$; por meio da equação $Q S=U_{i}$ - $U_{f}$ foram obtidos os volumes de água a serem aplicados em cada tratamento. A pesagem dos vasos foi realizada diariamente e sempre no mesmo horário.

Para estimar os valores da CE da solução nutritiva e os totais de sais dissolvidos, utilizou-se como referência a solução nutritiva de Furlani (1999), previamente testada (Beckmann-Cavalcante et al., 2009), que contém: macronutrientes (mg L-1): 200 de N, 31 de P, 293 de K, 100 de Ca, 24 de $\mathrm{Mg}$ e 32 de S; e micronutrientes $\left(\mathrm{mg} \mathrm{L}^{-1}\right)$ : 0,2 de B, 0,03 de $\mathrm{Cu}, 3,4$ de Fe, 1,1 de Mn, 0,05 de Mo e 0,2 de Zn. Os valores de CE das soluções nutritivas foram obtidos a partir da variação proporcional da concentração de cada nutriente de forma crescente, diluindo-se com água de chuva $\left(\mathrm{CE}=0,07 \mathrm{dS} \mathrm{m}^{-1}\right)$ até atingir a $\mathrm{CE}$ desejada, da seguinte maneira: $1=\mathrm{CE}_{1}$, solução de referência; $2=\mathrm{CE}_{2}$, com acréscimo de $33,33 \%$ da $\mathrm{CE}_{1} ; 3=\mathrm{CE}_{3}$, com acréscimo de $66,66 \%$ da $\mathrm{CE}_{1} ; 4=\mathrm{CE}_{4}$, com acréscimo de $100 \%$ da $\mathrm{CE}_{1}$; e $5=\mathrm{CE}_{5}$, com acréscimo de $133,33 \%$ da $\mathrm{CE}_{1}$.

Como fontes de nutrientes foram utilizados: nitrato de amônio $\left(\mathrm{NH}_{4} \mathrm{NO}_{3}\right)$, nitrato de cálcio $\left(\mathrm{Ca}\left(\mathrm{NO}_{3}\right)_{2}\right)$, nitrato de potássio $\left(\mathrm{KNO}_{3}\right)$, sulfato de magnésio $\left(\mathrm{MgSO}_{4}\right)$, monoamônio fosfato (MAP), Profol ${ }^{\circledR}(\mathrm{B} 10 \%$, Cu $14 \%$, Mn $14 \%$, Mo $12 \%$, Zn $24 \%$ ) e Rexene ${ }^{\circledR}$ (6,5 \% Quelato Ferro EDTA). Para evitar desequilíbrios nas soluções nutritivas, os valores de $\mathrm{CE}$ e de $\mathrm{pH}$ foram monitorados semanalmente.

A lavagem do substrato, nos tratamentos "com lixiviação", foi realizada de acordo com o método "PourThru", descrito por Cavins et al. (2000), a cada 14 dias. Inicialmente, procedeu-se à irrigação diária com solução nutritiva, deixando o substrato saturado; uma hora depois, foram adicionados $100 \mathrm{~mL}$ de água destilada aos vasos. Colocaram-se recipientes de plástico abaixo de quatro vasos de cada tratamento para coleta da solução lixiviada, a fim de se proceder à leitura do $\mathrm{pH}$ e da $\mathrm{CE}$, segundo recomendações do mesmo autor. 
Durante todo o ciclo da cultura foram consumidos em média 221 e $237 \mathrm{~mL}$ de solução nutritiva por vaso por dia, nos tratamentos SSL e SCL, respectivamente, independentemente dos valores de condutividade elétrica da solução nutritiva. Aos $14,28,42,56$ e 70 DAE houve consumo de 180, 200, 233, 244 e $249 \mathrm{~mL} /$ vaso $\mathrm{dia}^{-1}$, respectivamente, para SSL e de $181,217,254,266$ e 271, respectivamente, para SCL. No tratamento SCL, não foi considerada no consumo total a quantidade de água destilada aplicada na lixiviação dos sais.

\section{Variáveis estudadas}

O crescimento da cultura foi acompanhado a cada 14 DAE, registrando-se: (a) altura de plantas; (b) área foliar: pelo medidor de área foliar eletrônico (Li-Cor, L1-3100 ${ }^{\circledR}$ ); (c) diâmetro da haste; (d) diâmetro do buquê; (e) massa da parte aérea e da raiz seca: material submetido à secagem em estufa com circulação forçada de ar a $70^{\circ} \mathrm{C}$ por $72 \mathrm{~h}$ e pesado em balança analítica digital. Aos $70 \mathrm{DAE}$, foi registrado o número de botões com cor e o número de inflorescências abertas.

\section{Avaliação estatística}

Os dados foram submetidos à análise de variância, para verificação de efeitos dos fatores isolados e da interação entre ambos. As médias referentes aos fatores lixiviação do substrato e as épocas de avaliação em cada valor de CE foram comparadas pelo teste de Tukey $(p<0,01)$ no software SAS, e as relativas à condutividade elétrica do substrato, por regressão polinomial no software SIGMAPLOT.

\section{RESULTADOS E DISCUSSÃO}

Pelos resultados da análise de variância (Quadro 1), observam-se diferenças significativas entre os substratos sem (SSL) e com lixiviação (SCL) para todas as variáveis dependentes estudadas. Quanto aos valores de condutividade elétrica da solução nutritiva (CEs), excetuando-se diâmetro de haste, diâmetro do buquê e massa de raiz seca (Quadro 1), as demais variáveis apresentaram respostas significativas. Houve efeito de interação entre a $\mathrm{CE}$ das soluções e a lixiviação do substrato sobre a altura de plantas, o número de botões e o número de inflorescências (Quadro 1).

\section{Condutividade elétrica e período de avaliação}

O aumento da CE da solução nutritiva provocou inibição do crescimento em altura das plantas, independentemente da lavagem ou não do substrato para a lixiviação dos sais (Figura 1a). Embora as médias de altura das plantas tenham sido sempre superiores no substrato com lixiviação, neste as plantas apresentaram decréscimo gradativo até a CE de $2,8 \mathrm{dS} \mathrm{m}^{-1}$ e progressivo a partir da CE de $3,5 \mathrm{dS} \mathrm{m}^{-1}$, enquanto no substrato sem lixiviação as plantas apresentaram alturas inferiores, porém com decréscimos menos acentuados. A maior altura foi registrada nas plantas cultivadas em SCL irrigadas com solução de $\mathrm{CE}$ de $2,1 \mathrm{dS} \mathrm{m}^{-1}$, ou seja, um incremento de $20 \%$ em relação às plantas cultivadas no SSL sob a mesma CE. Já a menor altura média $(19,16 \mathrm{~cm})$ no substrato com lixiviação (SCL) ocorreu no tratamento submetido à solução de maior salinidade (CE de 4,9 dS m-1).

Quadro 1. Altura de plantas (ALT), área foliar (AF), diâmetro da haste (DH), diâmetro do buquê (DB), número de botões (NB), número de inflorescências (NI), massa da parte aérea seca (MSPA) e massa da raiz seca (MSR) em plantas de crisântemo cv. Miramar aos 70 DAE, em função da lixiviação da solução do substrato (L) e dos valores de condutividade elétrica da solução nutritiva (CEs)

\begin{tabular}{|c|c|c|c|c|c|c|c|c|}
\hline Causa de variação & ALT & $\mathrm{AF}$ & DH & DB & NB & NI & MSPA & MSR \\
\hline & $\mathrm{cm}$ & $\mathrm{cm}^{2}$ & $\mathrm{~mm}$ & $\mathrm{~cm}$ & \multicolumn{2}{|c|}{ - vaso } & \multicolumn{2}{|c|}{$\mathrm{g} /$ vaso } \\
\hline Lixiviação (L) (valor "F") & $33,30 * *$ & $7,96 * *$ & $4,73^{*}$ & $5,63^{*}$ & $10,88^{* *}$ & $867,00 * *$ & $50,25 * *$ & $21,34^{* *}$ \\
\hline SSL & $19,12 \mathrm{~b}$ & $1333,12 \mathrm{~b}$ & $3,81 \mathrm{a}$ & $23,85 \mathrm{~b}$ & $16,00 \mathrm{~b}$ & $6,75 \mathrm{~b}$ & $16,32 \mathrm{~b}$ & $2,35 \mathrm{~b}$ \\
\hline $\mathrm{SCL}$ & $21,55 \mathrm{a}$ & $1658,95 \mathrm{a}$ & $3,68 \mathrm{~b}$ & $24,93 \mathrm{a}$ & $17,35 \mathrm{a}$ & $11,85 \mathrm{a}$ & $22,07 \mathrm{a}$ & 3,16 a \\
\hline DMS & 0,86 & 235,93 & 0,13 & 0,92 & 0,84 & 0,35 & 1,66 & 0,19 \\
\hline CEs (valor "F") & $8,52^{* *}$ & $11,62 * *$ & $0,78^{\text {ns }}$ & $2,66^{\mathrm{ns}}$ & $22,07 * *$ & $1614,29 * *$ & $15,76^{* *}$ & $2,29^{\mathrm{ns}}$ \\
\hline Interação L x CEs (valor “F”) & $2,99^{*}$ & $0,62^{\mathrm{ns}}$ & $0,14^{\mathrm{ns}}$ & $0,40^{\mathrm{ns}}$ & $44,84^{* *}$ & $41,79 * *$ & $0,63^{\mathrm{ns}}$ & $0,35^{\mathrm{ns}}$ \\
\hline $\mathrm{CV}(\%)$ & 6,55 & 24,40 & 5,37 & 5,88 & 7,76 & 5,89 & 13,35 & 20,21 \\
\hline
\end{tabular}

**: significativo a 1\%; ns: não significativo ( $>$ > 0.05); DMS: diferença mínima significativa; CV: coeficiente de variação; SSL: substrato sem lixiviação; SCL: substrato com lixiviação; CEs: condutividade elétrica da solução nutritiva. *: significativo a 5 \%. 
Para o crescimento em altura das plantas em função do tempo (Figura 2a,b), observa-se que até os 28 DAE houve incremento na altura com o aumento da CE tanto em SSL quanto em SCL. De acordo com Gruszynski (2001), sobretudo nas primeiras seis semanas, as plantas de crisântemo crescem rapidamente e são altamente exigentes em nutrientes, principalmente em $\mathrm{N}$ e $\mathrm{K}$, o que justifica a maior altura das plantas na maior CE nesse período. A partir dos 42 DAE houve uma inversão, isto é, a altura nos menores valores de $\mathrm{CE}$ superou a dos dois maiores $\left(4,2\right.$ e $\left.4,9 \mathrm{dS} \mathrm{m}^{-1}\right)$, especialmente nas plantas em SCL (Figura 2b). Essa situação mostra que o aumento dos valores de CE intensifica o efeito osmótico da solução, ou seja, a maior concentração de sais no substrato reduz a absorção de água e aumenta a de sais pelas plantas, a ponto de comprometer processos fisiológicos (Kashem et al., 2000; Silva et al., 2004).

Resultados semelhantes foram encontrados para outras plantas ornamentais, como no estudo de Terceiro Neto et al. (2004) para a violeta-africana (Saintpaulia ionantha Wendl) e no de Carter et al. (2005) para a celósia (Celosia argentea).

No cultivo em vaso, a relação altura de planta e tamanho de vaso é um critério adotado para formar um conjunto harmônico e deve ser de 1,5 a 2 vezes a altura do vaso (Barbosa, 2003). No presente trabalho, as plantas cultivadas em SCL (Figura 2b), aos $70 \mathrm{DAE}$, em todos os valores de CE apresentaram alturas dentro da faixa referida, em especial pelas plantas nas CEs de 2,1, 2,8 e 3,5 $\mathrm{dS} \mathrm{m}^{-1}$, que apresentaram, respectivamente, 24,01, 23,11 e $22,03 \mathrm{~cm}$. Quanto às plantas em SSL (Figura 2a), somente as irrigadas com soluções de CE de 2,1 até $3,5 \mathrm{dS} \mathrm{m}^{-1}$ tiveram crescimento dentro do tamanho exigido pelo mercado, porém com aspecto visual não satisfatório, ou seja, as plantas não se apresentaram compactas e com boa ramificação. Essa situação indica a necessidade de lixiviação do substrato, como meta para produção de crisântemo com altura de haste compatível com as exigências de mercado.

Para a área foliar, observa-se comportamento semelhante ao da altura de plantas, inclusive com melhor ajuste ao modelo cúbico (Figura $1 \mathrm{~b}$ ). $\mathrm{O}$ aumento da CE resultou em declínio marcante da área foliar, registrando-se uma redução de aproximadamente $51 \%$ do menor para o maior valor de CE.

Em função do tempo, observa-se que até os $14 \mathrm{DAE}$ houve aumento na área foliar conforme se aumentou o valor de CE, tanto em SSL quanto em SCL (Figura 2c,d). Essa condição pode estar associada ao crescimento acelerado nas primeiras semanas (Gruszynski, 2001), bem como aos incrementos de sais iniciais no substrato. A partir de $28 \mathrm{DAE}$, observa-se que o aumento dos valores de $\mathrm{CE}$ causou redução da área foliar tanto em SSL quanto em SCL, porém os maiores valores sempre foram obtidos nos tratamentos SCL. Nota-se que aos $28 \mathrm{DAE}$ as plantas sob fertirrigação com CE de $2,1 \mathrm{dS} \mathrm{m}{ }^{-1} \mathrm{em} \mathrm{SCL}$ atingiram valores, da mesma ordem, das plantas cultivadas na mesma condutividade em SSL aos 70 DAE.

A redução no potencial osmótico, provocada pelo aumento da salinidade, e consequentemente no potencial hídrico causa inibição do crescimento vegetal e da fotossíntese, acúmulo excessivo de íons, causando toxicidade, inibição da divisão celular e da síntese de
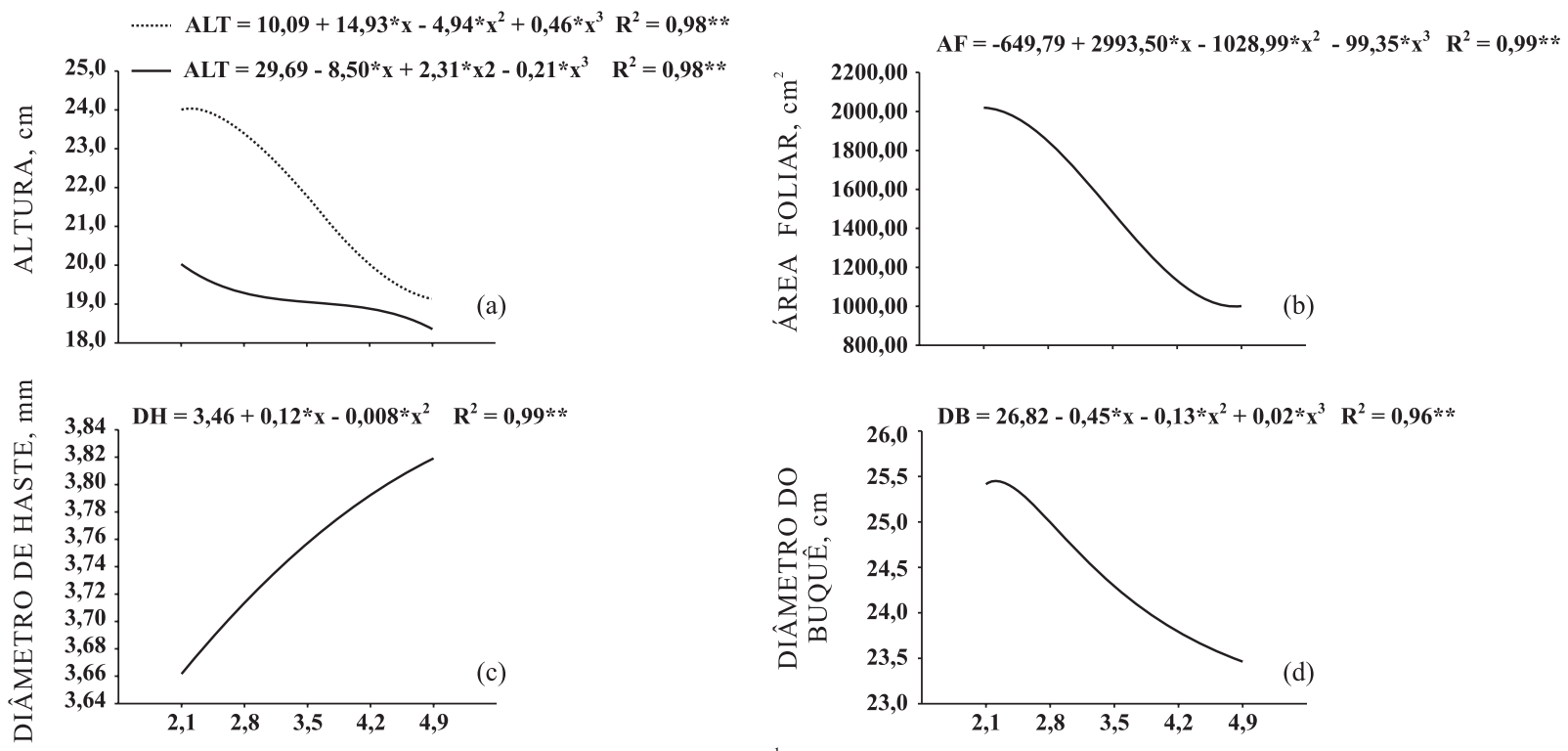

Figura 1. Altura de plantas [(-) substrato sem lixiviação; (…) substrato com lixiviação] (a), área foliar (b), diâmetro de haste (c) e diâmetro do buquê (d) de plantas de crisântemo cv. Miramar aos 70 DAE, em função dos valores de condutividade elétrica da solução nutritiva (CEs). 

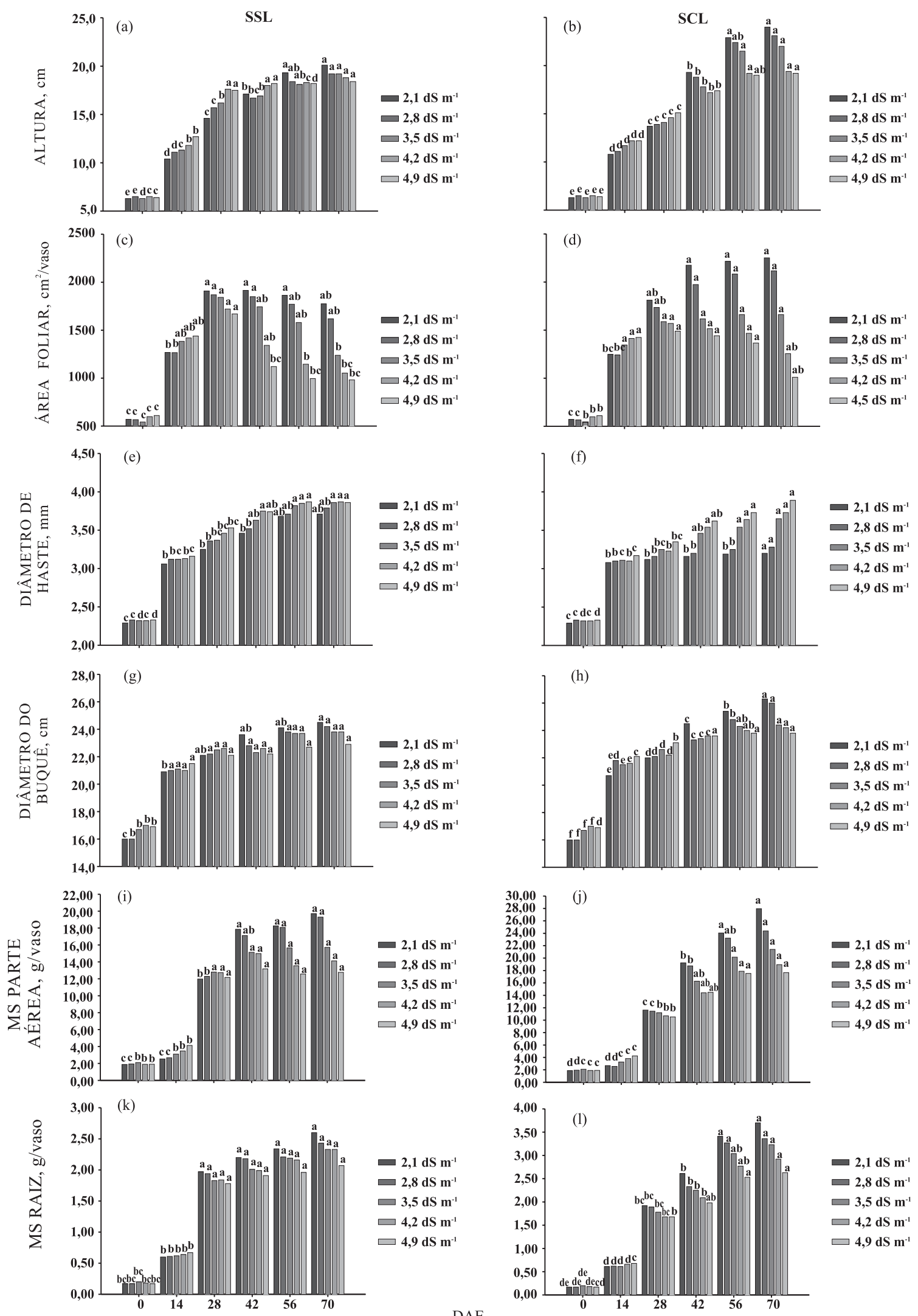

Figura 2. Crescimento de plantas de crisântemo cv. Miramar aos 0, 14, 28, 42, 56 e 70 dias após enraizamento (DAE) sob diferentes valores de condutividade elétrica (CE) da solução nutritiva em substrato sem (SSL) e com lixiviação (SCL). *Letras comparam as épocas de avaliação entre si em cada valor de CE, significância a $5 \%$. 
proteínas, com reflexos na redução da área foliar (Taiz \& Zeiger, 2004). Adicionalmente, vários autores confirmam a redução da área foliar em diferentes culturas com o incremento da concentração de sais na solução nutritiva ou água de irrigação, como em roseiras (Raviv \& Blom, 2001) e pepino (Chartzoulakis, 1994).

Houve aumento do diâmetro de haste, característica que confere rigidez à haste, em função dos níveis de CEs (Figura 1c). Esses resultados são concordantes com os de Shillo et al. (2002) e Paradiso et al. (2003), que observaram que o incremento de sais na água de irrigação aumentou o diâmetro de hastes de crisântemo, lisianto (Eustoma grandiflorum) e gérbera de corte. Essa situação pode ser atribuída ao fato de que o caule não acumula nutrientes na mesma proporção que as folhas, possui transpiração menor em relação a elas (Sonneveld, 2000) e, portanto, não é expressivamente prejudicado com os efeitos do aumento de sais na solução nutritiva. Com o passar do tempo (Figura 2e,f), as plantas cultivadas em SSL apresentaram incremento no diâmetro de haste até os 28 DAE, estabilizando a partir dos 42 DAE, bem como em SCL.

O diâmetro do buquê apresentou tendência de declínio em função do acréscimo da CE (Figura 1d). Verificou-se diferença estatística entre as épocas avaliadas, tanto para SSL quanto para SCL (Figura 2g,h). No entanto, vale ressaltar que a maior média do diâmetro do buquê foi obtida em plantas cultivadas no tratamento SCL na CE de $2,1 \mathrm{dS} \mathrm{m}^{-1}$, com $26,30 \mathrm{~cm}$.

As variáveis área foliar e diâmetro do buquê apresentaram correlação significativa entre si $\left(r=0,98^{* *}\right)$. Essa situação mostra que a redução da área foliar implica diminuição do diâmetro do buquê e, consequentemente, na qualidade do produto. Segundo Sonneveld (2000), o aumento da CE do substrato pode diminuir progressivamente o crescimento da cultura, a área foliar e o número de folhas. Especificamente para o crisântemo, essa inconveniência pode resultar em menor expansão do diâmetro do buquê.

$\mathrm{O}$ incremento nos valores de $\mathrm{CE}$ também resultou na redução da produção de botões florais e inflorescências aos 70 DAE, implicando perda de qualidade de plantas de crisântemo. Sob cultivo em SSL percebe-se que o aumento nos valores da CE reduziu a quantidade de botões emitidos, enquanto SCL promoveu acréscimo no número de botões nas plantas (Figura 3a). Adicionalmente, no cultivo em SSL houve presença de inflorescências abertas das CEs de 2,1 até $3,5 \mathrm{dS} \mathrm{m}^{-1}$. Comparativamente com o SCL, registrou-se produção de flores em todas as CEs, mas com maior número de inflorescências (22) nos tratamentos com CE de $2,1 \mathrm{dS} \mathrm{m}^{-1}$ (Figura 3b).

Nas plantas cultivadas em SCL, o menor número de botões com cor foi inversamente proporcional ao número de inflorescências. Entretanto, no SSL, a produção de ambos diminuiu conforme aumentaram os valores de CEs, o que concorda com os resultados de Baas et al. (1995) para gérbera de corte e de De Kreij \& van der Berg (1990) para rosa de corte. Assim, o acúmulo de sais na rizosfera pode provocar desequilíbrio fisiológico nas plantas (Ayers \& Westcot, 1999) e, consequentemente, reduzir a produção de botões e inflorescências de plantas ornamentais, bem como provocar atraso na abertura das flores (Sonneveld, 2000).

A produção de massa da parte aérea seca (MSPA), foi estatisticamente reduzida em aproximadamente $36 \%$ da CE de $2,1 \mathrm{dS} \mathrm{m}^{-1}$ para a de $4,9 \mathrm{dS} \mathrm{m}^{-1}$ (Figura 3c). Quanto à produção de massa das raízes secas, apesar da ausência de efeitos significativos, observa-se (Figura 3d) que também ocorreu queda na biomassa das raízes secas em função do incremento da CE. Assim, Hu \& Schmidhalter (2004) argumentam que, sob condições de estresse salino, as raízes podem sofrer diminuição no alongamento e suberização, refletindo em menor absorção de água e aumento das concentrações de sais, fechamento dos estômatos (comprometendo seriamente a fotossíntese) e diminuição da translocação de nutrientes da raiz para a parte aérea, além de perdas na produção de matéria seca.

O sistema radicular constitui um dos mais importantes fatores para avaliação de salinidade devido ao fato de as raízes estarem em contato direto com os sais e absorverem a solução do solo (Storey et al., 2003). Contudo, Munns (2000) afirma que pouco se sabe a respeito do efeito da CE sobre o sistema radicular, uma vez que os resultados são variáveis e específicos quanto à espécie.

A produção da massa de parte aérea seca (Figura 2i) em SSL aumentou significativamente até 28 DAE, estabilizando-se a partir de 42 DAE em todas as CEs. Já para SCL (Figura 2j) houve aumento na produção de MSPA até 42 DAE, estabilizando-se aos 56 DAE. Cabe salientar que aos 70 DAE, em SCL, ocorreu a maior média de produção de MSPA $(27,97 \mathrm{~g} /$ vaso) para CE de $2,1 \mathrm{dS} \mathrm{m}^{-1}$, com aumento de aproximadamente $37 \%$ em relação à $\mathrm{CE}$ de $4,9 \mathrm{dS} \mathrm{m}^{-1}$. Em referência à MSR, verificou-se diferença significativa entre as épocas avaliadas tanto para SSL (Figura $2 \mathrm{k}$ ) quanto para SCL (Figura 2l), observando-se que ocorre tendência à redução conforme aumentam os valores de CE, a partir dos 28 DAE. Esses resultados demonstram intensificação do efeito deletério do acúmulo de sais no substrato com a idade das plantas, revelando a necessidade de monitoramento da solução fornecida durante o ciclo do crisântemo.

Respostas negativas da condutividade elétrica da água de irrigação sobre a massa da parte aérea seca também foram observadas em plantas ornamentais, como Begonia, Chlorophytum, Coleus e Geranium (Zurayk et al., 1993). Para a massa de raiz seca, foram observados decréscimos também em crisântemo (Prabucki et al., 1999) e em maracujazeiro (Cavalcante et al., 2002). 

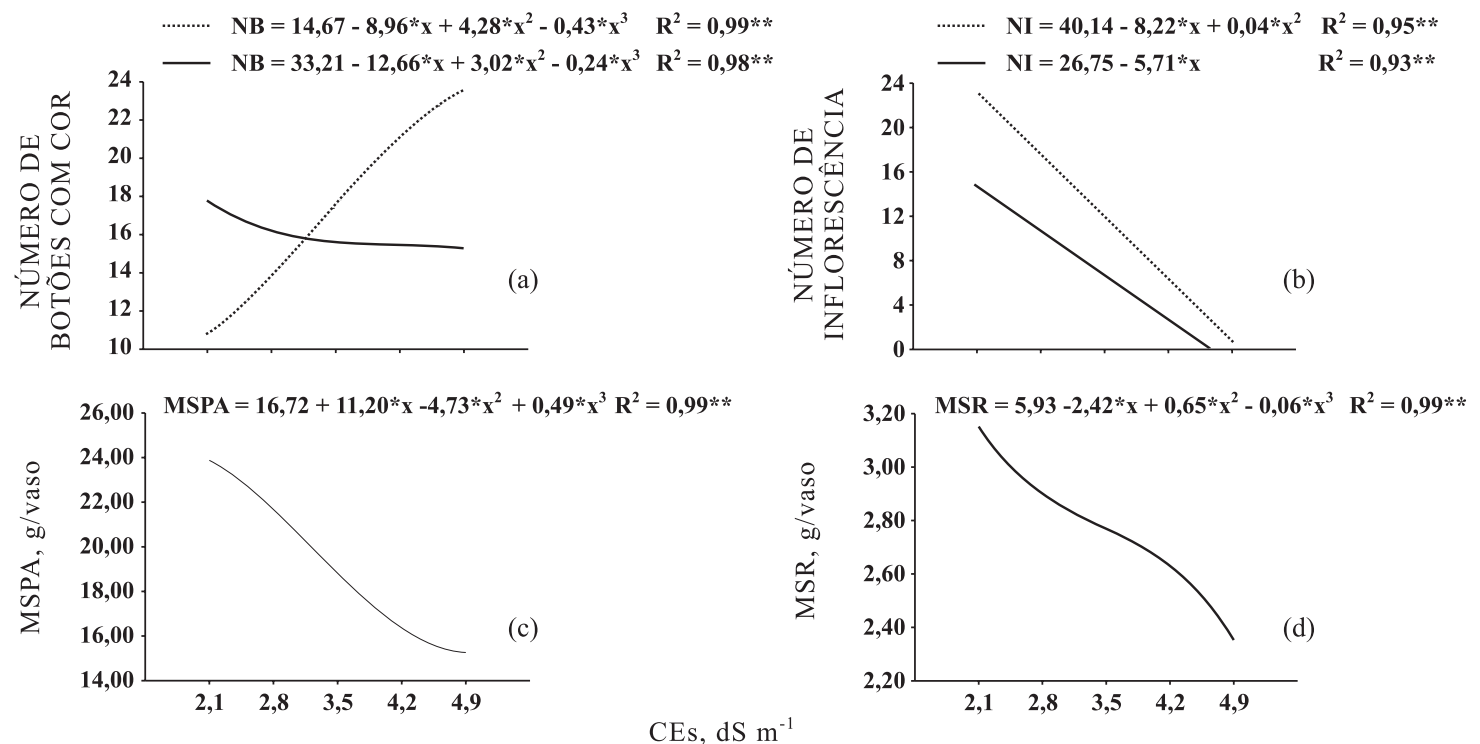

Figura 3. Número de botões com cor por vaso (a); número de inflorescências por vaso (b); massa da parte aérea seca (MSPA) (c) e massa da raiz seca (MSR) (d) de plantas de crisântemo cv. Miramar aos 70 DAE, em função dos valores de condutividade elétrica da solução nutritiva (CEs) [(一) substrato sem lixiviação; (….) substrato com lixiviação].

\section{Lixiviação versus crescimento}

O crescimento das plantas de crisântemo foi estatisticamente influenciado pelo cultivo em SSL e SCL, promovendo, de modo geral, redução significativa em altura de plantas, área foliar, diâmetro de buquê, número de botões e de inflorescências, massa da parte aérea e da raiz secas quando submetidas ao SSL, com exceção do diâmetro de haste (Quadro 1).

Os valores de CEs aplicados às plantas promoveram aumento na concentração de sais da solução lixiviada do substrato tanto em SSL quanto em SCL, com incremento de aproximadamente $29 \%$ no SSL em relação ao SCL aos $70 \mathrm{DAE}$, quando aplicada a CE de 4,9 dS m ${ }^{-1}$ (Figura 4). A menor CE obtida em SCL em relação à SSL deve-se à aplicação com água destilada a cada $14 \mathrm{DAE}$, a qual provocou a lixiviação ou diluição de sais no substrato, reduzindo o acúmulo na zona radicular do substrato.

Possivelmente, a redução no crescimento em consequência da elevação da CE da solução lixiviada no substrato seja resultante, segundo Rains (1984), da transferência de energia, que seria usada no crescimento da planta, para a tentativa de ajustamento osmótico. Segundo Parida \& Das (2005), os sais no solo podem alterar o crescimento das plantas por meio de efeito osmótico, tóxico e de natureza nutricional. No presente estudo, admite-se que o efeito mais prejudicial tenha sido o osmótico devido à não contemplação de íons com efeitos específicos, a exemplo de $\mathrm{Na}$ e $\mathrm{Cl}$, na solução aplicada.

Em complemento, Bresler \& Hoffman (1986) afirmam que o potencial osmótico da solução nutritiva é um dos fatores que influenciam a absorção de água e nutrientes pelas plantas por meio do sistema radicular.

As faixas de condutividade elétrica da solução lixiviada consideradas adequadas para o crisântemo, pelo método da lixiviação ou PourThru, estão situadas entre 2,6 e 4,6 dS m${ }^{-1}$ (Cavins et al., 2000). Dessa forma, pelos resultados da figura 4 , verifica-se que apenas os substratos irrigados com as soluções de CEs de 2,1, 2,8 e 3,5 $\mathrm{dS} \mathrm{m}^{-1}$ do SCL encontram-se dentro da faixa recomendada, mas somente as plantas cultivadas em SCL na CE de $2,1 \mathrm{dS} \mathrm{m}^{-1}$ estavam dentro de padrões qualitativos, ou seja, plantas compactas, com boa ramificação, parte aérea bem formada, proporcionalidade planta:vaso (altura da

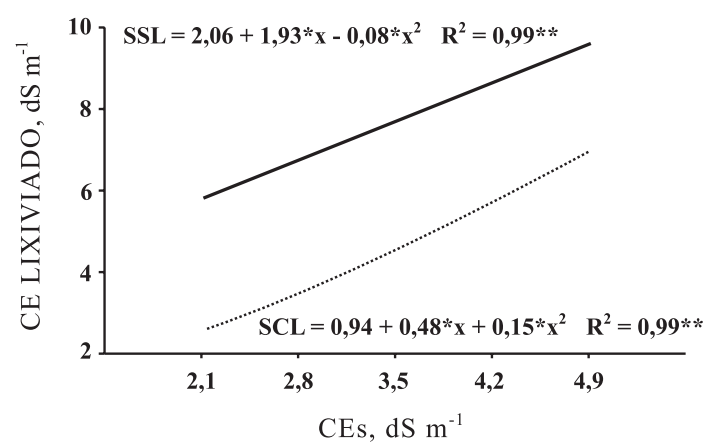

Figura 4. Condutividade elétrica do lixiviado aos 70 dias após o enraizamento (DAE) em cultivo com plantas de crisântemo cv. Miramar sob diferentes valores de condutividade elétrica da solução nutritiva em substrato sem (SSL) e com lixiviação (SCL). 
planta de 1,5 a 2 vezes a altura do vaso), estabilidade na composição, caule firme e com boa sustentação, plantas bem enraizadas e firmes no vaso (Motos \& Oliveira, s.d.; Barbosa, 2003). Portanto, como no cultivo em vaso, de modo geral, realizado em ambiente protegido, o risco de salinização é maior, devido à ausência da precipitação e adição de lâminas de água, torna-se necessária a aplicação de água destilada para promover a extração ou lixiviação de sais solúveis na zona radicular, conforme também inferiu Burgueño (1996), confirmando que a lixiviação garante alta disponibilidade de nutrientes sem a ocorrência de problemas osmóticos.

\section{CONCLUSÕES}

1. A condutividade elétrica (CE) da solução nutritiva interfere no crescimento do crisântemo, tornando-se mais deletéria à medida que aumenta a idade das plantas; assim, é benéfico reduzir a concentração de sais da solução nutritiva com o tempo.

2. A solução nutritiva com $\mathrm{CE}$ de $2,1 \mathrm{dS} \mathrm{m}^{-1}$ possibilita a produção de crisântemo cv. Miramar dentro de padrões produtivos e qualitativos de comercialização, mediante a lixiviação periódica da solução do substrato com água.

\section{AGRADECIMENTOS}

À Coordenação de Aperfeiçoamento de Pessoal de Nível Superior (CAPES), pelo apoio financeiro para desenvolvimento da pesquisa por meio da concessão de bolsa.

\section{LITERATURA CITADA}

AYERS, R.S. \& WESTCOT, D.W. A qualidade da água na agricultura. Campina Grande, Universidade Federal da Paraíba, 1999. 153p.

BAAS, R.; NIJSSEN, H.M.C.; van den BERG, T.J.M. \& WARMENHOVEN, M.G. Yield and quality of carnation (Dianthus caryophyllus L.) and gerbera (Gerbera jamesonii L.) in a closed nutrient system as affected by sodium chloride. Sci. Hortic., 61:273-284, 1995.

BARBOSA, J.G. Crisântemos: Produção de mudas, cultivo para corte de flor, cultivo em vaso e cultivo hidropônico. Viçosa, MG, Aprenda Fácil, 2003. 232p.

BECKMANN-CAVALCANTE, M.Z.; PIVETTA, K.F.L.; CAVALCANTE, Í.H.L.; CAVALCANTE， L.F. \& BELLINGIERI, P.A. Soluções nutritivas no desenvolvimento do crisântemo cultivado em vaso. Irriga, 14:205 219, 2009.

BRESLER, E. \& HOFFMAN, G.J. Irrigation management for soil salinity control: Theories and tests. Soil Sci. Soc. Am. J., 50:1552-1560, 1986.
BURGUEÑO, H. La fertirrigación en cultivos hortícolas con acolchado plástico. Mexico, Culiacan, 1996. 45p.

CARTER, C.T.; GRIEVE, C.M.; POSS, J.A. \& SUAREZ, D.L. Production and ion uptake of Celosia argentea irrigated with saline wastewaters. Sci. Hortic., 106:381-394, 2005.

CAVALCANTE, L.F. \& CAVALCANTE, I.H.L. Uso da água salina na agricultura. In: CAVALCANTE, L.F. \& LIMA, E.M. Algumas frutíferas tropicais e a salinidade. Jaboticabal, FUNEP, 2006. p.1-18.

CAVALCANTE, L.F.; SANTOS, J.B.; SANTOS, C.J.O.; FILHO, J.C.F.; LIMA, E.M. \& CAVALCANTE, I.H.L. Germinação de sementes e crescimento inicial de maracujazeiros com água salina em diferentes volumes de substrato. R. Bras. Frutic., 24:748-751, 2002.

CAVINS, T.J.; WHIPKER, B.E.; FONTENO, W.C.; HARDEN, B.; McCALL, I. \& GIBSON J.L. Monitoring and managing $\mathrm{pH}$ and EC using the PourThru extraction method. Hortic. Infor. Leaflet, 590:1-17, 2000.

CHARTZOULAKIS, K.S. Photosynthesis, water relations and leaf growth of cucumber exposed to salt stress. Sci. Hortic., 59:27-31, 1994.

DE KREIJ, C. \& van den BERG, T.J.M. Nutrient uptake, production and quality of Rosa hybrida in rockwool as affected by electrical conductivity of the nutrient solution. In: van BEUSICHEM, M.L. Plant nutrition, physiology and applications. Dordrecht, Kluwer Academic Publishers, 1990. p.519-523.

FURLANI, P.R. Hydroponic vegetable production in Brazil. Acta Hortic., 481:777-778, 1999.

GRUSZYNSKI, C. Produção comercial de crisântemos: Vaso, corte e jardim. Guaíba, Agropecuária, 2001. 166p.

HU, Y. \& SCHMIDHALTER, U. Limitation of salt stress to plant growth. In: HOCK, E. Plant toxicology. 4.ed. New York, Marcel Dekker, 2004. p.191-224.

KASHEM, M.A.; SULTANA, N.; IKEDA, T.; HORI, H.; LOBODA, T. \& MITSUI, T. Alteration of starch-sucrose transition in germinating wheat seed under sodium chloride salinity. J. Plant Biol., 43:121-127, 2000.

MOTOS, J.R. \& OLIVEIRA, M.J.G. Produção de crisântemos em vaso. Holambra, Flortec, (s.d.). 34p.

MUNNS, R. Comparative physiology of salt and water stress. Plant Cell Environ., 25:239-250, 2000.

NELL, T.A.; BARRET, J.E. \& LEONARD, R.T. Production factor affecting post production quality of flowering potted plants. HortScience, 32:817-819, 1997.

PARIDA, A.K. \& DAS, A.B. Salt tolerance and effects on plants: A review. Ecotoxicol. Environ. Saf., 60:324-349, 2005

PARADISO, R.; De PASCALE, S.; APREA, F. \& BARBIERI, G. Effect of electrical conductivity levels of nutrient solution on growth, gas exchanges and yield of two gerbera cultivars in soiless system. Acta Hortic., 609:165-171, 2003. 
PRABUCKI, A.; SEREK, M. \& ANDERSEN, A.S. Influence of salt stress on stock plant growth and cutting performance of Chrysanthemum morifolium Ramat. J. Hortic. Sci. Biotechnol., 74:132-134, 1999.

RAINS, D.W. Metabolic energy cost for plant cells exposed to salinity. California Agric., 1:22, 1984.

RAVIV, M. \& BLOM, T.J. The effect of water availability and quality on photosynthesis and productivity of soiless grow cut roses. Sci. Hortic., 88:257-276, 2001.

RÖBER, R. Advances in nutrition and fertilization of cut flowers in relationship to environmental considerations. Acta Hortic., 482:351-362, 1999.

SHILLO, R.; DING, M.; PASTERNAK, D. \& ZACCAT, M. Cultivation of cut flower and bulb species with saline water. Sci. Hortic., 92:41-54, 2002.

SILVA, C.M.; MONTER, Á.V.; GARCÍA, P.S.; GONZÁLEZ, G.A.; MENDOZA, M.N.R. \& POSADAS, L.M.R. Efecto del potencial osmótico y contenido de $\mathrm{Ca}$ em el medio de cultivo sobre la distribución de $\mathrm{Ca}^{2+} \mathrm{y} \mathrm{K}^{+}$, producción de biomasa y necrosis apical de vid "R110". Interciencia, 29:384-388, 2004.
SONNEVELD, C. Effects of salinity on substrate grown vegetables and ornamentals in greenhouse horticulture. Wageningen, Wageningen University, 2000. 150p. (Tese de Doutorado)

STOREY, R.; SCHACHTMAN, D.P. \& THOMAS, M.R. Root structure and cellular chloride, sodium and potassium distribution in salinized grapevines. Plant Cell Environ., 26:789-800, 2003.

TAIZ, L. \& ZEIGER, E. Fisiologia vegetal. 3.ed. Porto Alegre, Artmed, 2004. 719p.

TERCEIRO NETO, C.P.C.; HERNANDEZ, F.F.F.; BEZERRA, F.C.; SOUZA, R.F. \& CAVALCANTI, M.L.F. Efeito da concentração salina da solução nutritiva na aclimatação de plantas micropropagadas de violeta africana (Saintpaulia ionantha Wendl). R. Biol. Ci. Terra, 4:1-8, 2004.

ZURAYK, R.; TABBARAH, D. \& BANBUKIAN, L. Preliminary studies on the salt tolerance and sodium relation of common ornamental plants. J. Plant Nutr., 16:1309-1316, 1993. 